\title{
Dinâmica intraurbana e redes sociais na Baixada Santista
}

\author{
Tiago Augusto da Cunha* \\ José Marcos Pinto da Cunha* \\ Alberto Augusto Eichman Jakob
}

\begin{abstract}
Não é de hoje que diversos estudos atribuem grande importância à redistribuição espacial da população provocada a partir de movimentos migratórios nos processos de expansão urbana. Assim, o objetivo principal deste trabalho é destacar e delimitar ainda mais o estudo desses fluxos e movimentos, a partir da noção de redes sociais. Noção já largamente utilizada desde o final da década de 1970 em estudos sobre migração internacional, mas ainda pouco apropriada nos trabalhos sobre movimentos migratórios internos, principalmente os de curta distância, tais como os intrametropolitanos. Para tanto, são utilizados os dados de uma pesquisa domiciliar, realizada em 2007, a fim de levantar e analisar informações mais específicas sobre tais redes, uma vez que estas inexistem nas usuais fontes secundárias de dados. Dessa forma, a Região Metropolitana da Baixada Santista, além de ser encarada como recorte espacial, é também tomada como objeto de estudo do projeto temático "Vulnerabilidade das Metrópoles Paulistas". A pesquisa domiciliar realizada permite, ainda, análises intramunicipais e intraurbanas a partir das chamadas zonas de vulnerabilidade.
\end{abstract}

Palavras-chave: Redes sociais. Mobilidade intrametropolitana. Baixada Santista.

\footnotetext{
* Doutorando em Demografia, Departamento de Demografia, Instituto de Filosofia e Ciências Humanas - IFCH, Universidade Estadual de Campinas (UNICAMP) (ta_cunha@yahoo.com.br).

** Professor doutor em Demografia, Núcleo de Estudos de População - Nepo, da Universidade Estadual de Campinas Unicamp (zemarcos@nepo.unicamp.br).

${ }^{* * *}$ Pesquisador doutor em Demografia, Núcleo de Estudos de População - Nepo, da Universidade Estadual de Campinas Unicamp (alberto@nepo.unicamp.br).
} 


\section{Introdução}

O objetivo principal deste trabalho é destacar as principais características de migração na Região Metropolitana da Baixada Santista (RMBS) e avaliar a importância das redes sociais como mediadoras/condicionantes dos movimentos migratórios, sejam estes intramunicipais (ou melhor, intraurbanos ${ }^{1}$ ), intrametropolitanos ou externos à região metropolitana.

Não é de hoje que a migração é considerada um relevante fator transformador dos processos de redistribuição populacional, consequentemente, dos processos de expansão urbana, em especial os das regiões metropolitanas (RMs). Estudos como o de Cunha (1994), sobre a mobilidade e o processo de expansão da Região Metropolitana de São Paulo (RMSP), os de Matos (1994) e Rigotti e Rodrigues (1994), sobre a RM de Belo Horizonte, e os de Jakob (2003) e Cunha et al. (2006), sobre a região ora focada, atestam a importância da questão.

Todavia, mesmo sendo inequívoca a importância da migração para o completo entendimento dos processos de expansão urbana das regiões metropolitanas, suas motivações não são mais as mesmas de décadas anteriores. Baeninger (2000) menciona que os processos por trás das transformações ocorridas nos movimentos migratórios atuais têm suas raízes possivelmente nas últimas duas décadas do século XX, visto que a perspectiva histórico-estrutural sobre os incentivos e constrangimentos da migração, de acordo com os distintos desempenhos econômicos entre áreas de origem e destino (SINGER, 1980), alcançaram seus limites explicativos. Assim, outras questões e, consequentemente, outros elementos e fatores assumem relevante papel, em especial naquelas migrações mais localizadas espacialmente, prioritariamente entre áreas urbanas (U-U). O fato é que a diversidade/heterogeneidade do padrão migratório pós-80 requer a incorporação de outras e novas dimensões articuladas à realidade atual. Parece que os movimentos internos às RMs podem dar os primeiros indícios da existência e atuação desses outros mecanismos.

Nesse contexto, a noção de redes sociais pode ser central. Seria possível considerar sua influência mais um possível motivo/condicionante da migração de e para determinadas regiões? Além disso, em que medida as mesmas podem atuar nos processos de integração do migrante à região? Dessa forma, as redes sociais poderiam explicar a concentração de migrantes em determinadas áreas de destino ou ao menos o direcionamento de determinados fluxos migratórios?

Para se avaliar a importância das redes sociais nos movimentos migratórios e na estruturação dos espaços, dificilmente se pode contar com dados secundários, tendo em vista que estes, como os censos demográficos, por exemplo, não possuem informação direta

\footnotetext{
${ }^{1}$ Uma vez que aqui utilizaremos as zonas de vulnerabilidade como recorte mínimo de análise espacial, o mais correto seria empregar a terminologia migração intraurbana, haja vista que a pesquisa possibilita a captação de movimentos internos às áreas urbanas independentemente se estas ocorrem internamente aos municípios ou entre estes.
} 
a esse respeito. ${ }^{2}$ Assim, são poucos os trabalhos que tratam deste tema, em especial na análise da dinâmica intraurbana recente.

No caso da Baixada Santista, em 2007, esse “porém” foi em parte superado por meio de um levantamento domiciliar ${ }^{3}$ que serve a tal propósito, cujas informações foram utilizadas no presente trabalho.

Assim, a possibilidade de se contar com uma pesquisa recente e com informações específicas sobre o tema é uma oportunidade ímpar que contribui para o avanço dos estudos demográficos sobre migração interna e redes sociais no Brasil.

Tomando o caso da Região Metropolitana da Baixada Santista, em 2007, o presente estudo busca, portanto, retomar uma discussão que tem sido amplamente debatida no âmbito da migração internacional. Neste sentido, como será possível notar, a análise beneficiarse-á muito das reflexões teóricas e empíricas já realizadas, sem, no entanto, a pretensão de estabelecer uma forma acabada para enfocar a questão para o caso de mobilidade espacial ao nível do país, ou mesmo, como é o caso, de uma região metropolitana.

Trata-se, sim, de um primeiro passo que suscitará novas e mais profundas incursões para que o tema migração interna e redes sociais volte à baila como questão relevante para a melhor compreensão da mobilidade espacial da população em nosso país.

\section{Migração nas metrópoles e redes sociais: um campo a ser explorado}

Pouco se tem falado a respeito das redes sociais em termos regionais. A maior parte da literatura que demonstra sua relevância refere-se a movimentos de longa distância, tais como os internacionais. Exemplos são os dekasseguis que se destinam ao Japão (SAZAKI, 2000; HIRANO, 2008), ou ainda os fluxos migratórios de brasileiros para os Estados Unidos (FUSCO, 2002 e 2007).

Dois outros importantes estudos (SOARES, 2002; FAZITO, 2005) também tomam as migrações internacionais como objeto, proporcionando um notável ganho analítico, uma vez que, "para além da concepção metafórica de redes sociais", ${ }^{4}$ partem efetivamente para o mapeamento de redes sociais egocentradas dos migrantes. Neles, o trabalho de Hanneman e Riddle (2005) e as noções desenvolvidas por estes se fazem sentir com maior intensidade.

Já em relação aos movimentos migratórios internos à nação, dois outros estudos merecem especial atenção, pois, mesmo tratando de temas distintos do aqui trabalhado, o fazem por meio do instrumental oriundo das chamadas “Análises de Redes Sociais” (ARS). Além disso,

\footnotetext{
2 É bem verdade que alguns estudos tentam buscar aproximações sobre a questão a partir do Censo Demográfico utilizando, por exemplo, informações sobre famílias conviventes, existência de parentes no domicílio, etc. (CUNHA et al., 2006). No entanto, devemos ter consciência que se trata apenas de aproximações superficiais de um fenômeno bem mais complexo. Já trabalhos como os de Matos e Braga (2004) e Lima e Braga (2010), ao discutirem a rede urbana nacional, se valem de instrumentos específicos das Análises de Redes Sociais.

${ }^{3}$ Especificamente por meio do projeto temático "Vulnerabilidade das Metrópoles Paulistas", desenvolvido pelo Núcleo de Estudos de População (Nepo) da Universidade Estadual de Campinas.

${ }^{4}$ Em alusão direta ao título dado por Soares (2002) ao seu artigo.
} 
tais estudos têm como preocupação central a dinâmica migratória interna e o mapeamento dos seus fluxos na atualidade.

O primeiro, elaborado por Matos e Braga (2004), parte da “clássica” distinção histórico-estrutural nos estudos migratórios entre áreas de destino e origem de fluxos populacionais, ${ }^{5}$ a fim de melhor compreender o papel das localidades (municípios) na rede urbana e na rede migratória nacional.

Dada a heterogeneidade do padrão migratório brasileiro, principalmente a partir da década de 1980, os autores estão preocupados em indicar novas territorialidades, ou, como os próprios mencionam, "territorialidades emergentes" no contexto da rede de cidades/ localidades. A pergunta central aqui seria: os municípios "expulsores” (forças centrípetas) e "atratores" (forças centrífugas) de população pré-80 se mantêm após esse período? Se não, quais são estes novos polos? E, principalmente, quais são os motivos/mecanismos que estão por trás dessas transformações?

As trocas populacionais entre estas localidades são tomadas como "proxys" de interações espaciais, indicando potenciais áreas ou vetores de expansão, onde fatores sociais (mercado de trabalho e inovações socioeconômicas) estariam agindo com maior intensidade e dinamismo.

Já o segundo estudo é aquele desenvolvido por Lima e Braga (2010). Numa espécie de desdobramento da agenda de pesquisa anteriormente delineada por Matos e Braga (2004), aqui os autores se atêm a uma categorização mais precisa entre áreas que repelem e atraem população por meio de uma série de medidas, instrumentos e noções ainda correlacionada às ARS.

Dessa forma, os autores propõem uma metodologia de classificação dos municípios de acordo com "suas características migratórias", utilizando essencialmente: índice de eficácia migratória; grau de centralidade médio; saldo migratório; percentual de imigrantes; percentual de emigrantes; e população total. Tais características dariam indícios do papel dos municípios, principalmente daqueles de médio porte, na rede de cidades brasileiras a partir da diversificação dos fluxos migratórios vivenciada no período pós-80.

Assim, os autores concluem que há diferentes níveis de articulação das localidades brasileiras, onde a migração possui claro e inequívoco papel condicionante. Ou seja, "os novos padrões da migração caracterizam-se pela sobreposição de novas condições e novos lugares disponíveis para os movimentos, bem como de padrões antigos que se sustentam como efeito da inércia provocada pela estabilidade dos laços sociais entre os migrantes." (LIMA; BRAGA, 2010, p. 15, grifo nosso).

Por fim, o estudo proporciona interessantes inquietações. A imensa maioria das regiões metropolitanas apresenta índices de eficácia migratória marcadamente rotativos. Como ressaltado pelos próprios autores, estudos mais pormenorizados sobre estes recortes espaciais se fazem necessários, dado que as características dos municípios de uma mesma região metropolitana são deveras distintas entre si.

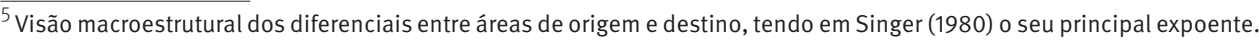


Ainda que a perspectiva adotada em cada um dos estudos supracitados em muito difira dos objetivos aqui traçados, são estes alguns exemplos de estudos nacionais que se preocupam em discutir as possíveis relações entre a noção de redes sociais e o processo migratório.

Recorrentemente, as explicações relativas ao processo migratório giram em torno de motivações macro ou microestruturais. Partindo de uma visão macro, em que fatores econômicos seriam elementos preponderantes na decisão sobre migrar ou não migrar, Borjas (1990) introduz o conceito de "global migration market". Segundo tal definição, o migrante, a partir de decisões individualizadas, sem, contudo, deixar de ser influenciado socialmente, calcularia de modo racional as vantagens entre migrar ou manter-se no local de origem. As vantagens, nesse caso, seriam proporcionadas pelo máximo retorno financeiro possível. Entretanto, o “cálculo" envolveria também outros elementos e fatores, tais como probabilidade de encontrar um bom emprego, custos materiais da viagem e a periculosidade da mesma, facilidade ou não de adaptação ao destino, fatores psicológicos e, por fim, mas não menos importante, fatores sociais. Uma vez que o saldo seja positivo, o migrante opta pela mudança.

Ainda assim, diversos autores, entre eles Sassen (1988), contradizem tal padrão de fluxo migratório - caracterizado por ser proveniente de países em desenvolvimento ou em estágios médios de desenvolvimento - que se direciona, unicamente, para países e/ou regiões mais desenvolvidas, tendo o elemento econômico (emprego) seu principal motivador. Como exemplo, a autora cita diversos fluxos inversos.

Os fatores econômicos, desse modo, exercem grande influência sobre as teorias de migração e, em certa medida, são elementos cruciais para sua compreensão. São, inclusive, fatores de fácil mensuração, configurando-se como poderosas ferramentas de análise das ações racionais, descritas anteriormente. No entanto, explicações que levem em conta somente fatores econômicos não completam o cabedal de questões que poderiam ser levantadas, tais como: por que um indivíduo decide pela migração enquanto seu parente próximo, em condições econômicas extremamente similares, nem a cogita como alternativa? Por que, mesmo em situações econômicas adversas no destino, o fluxo continua estruturado, podendo, inclusive, aumentar seu volume? É a partir de questionamentos muito similares a estes que outras noções, entre elas a de redes sociais, são incorporadas ao arcabouço teórico das migrações. Ademais, talvez assim se demonstre, até certo ponto, a importância das redes na estruturação e manutenção de determinados fluxos.

Desse modo, além de desconsiderar por completo a condição de classe do indivíduo - o que reputamos de fundamental importância -, a ação racional dos indivíduos, que agem em busca do maior benefício possível em proveito próprio, deixa de fora uma parte substancial da análise sobre a migração, ou seja, a própria análise da influência das relações sociais, uma vez que a decisão motivada pelas vantagens ou desvantagens do ato de migrar ou não migrar partiria de uma decisão individual. Fica claro, portanto, que não se compartilha deste ponto de vista individualizante do processo, uma vez que a decisão pessoal/individual também pode ser socialmente influenciada, ou melhor, socialmente orientada. Aqui, o comportamento 
individual seria condicionado, em grande medida, pelo comportamento social, ou da maioria, ou de seus semelhantes, de seus parentes, etc. (FUSCO, 2002).

A partir da constatação das limitações nas “clássicas” bases teóricas, surge a necessidade de sua reformulação, a partir de uma perspectiva sociológica que ocorreria em dois níveis distintos: o macroestrutural, que, além da situação de classe, consideraria as diferenças econômicas entre nações/regiões como catalisadoras essenciais da migração; e o microestrutural, este mais articulado a decisões individuais (PORTES, 1995; MARQUES, 2002).

Tal preocupação com esta escala intermédia de análise também pode ser encontrada no trabalho elaborado por Fusco (2002), em que o autor se propõe a desenvolver um estudo que objetiva discriminar a atuação das redes sociais no fluxo migratório entre a cidade mineira de Governador Valadares e os Estados Unidos.

Apesar de não possuir um quadro similar de conceitos para abordar as questões microestruturais, nas quais as diferenças intranacionais da propensão da migração entre indivíduos e comunidades devam ser analisadas, o conceito de redes sociais, ou social networks, tem sido cada vez mais enriquecido e utilizado. (FUSCO, 2002, p. 14)

Além disso, a partir dessa nova abordagem, outros fatores começam a ter maior destaque comparativamente ao fator econômico. Um desses fatores que ganham relevância significativa, se não a principal, é a própria família. Informações sobre mercado de trabalho, condições de vida no local de destino e aspectos jurídicos seriam fornecidas por fontes de confiança, ou ainda os denominados “laços fortes” (GRANOVETTER, 1973).

Assim, a unidade doméstica configura-se como uma relevante unidade de sustentação (provimento de recursos, ajudas e suportes), segundo termo cunhado por Boyd (1989), condicionando, em certa medida, tanto o ato de migrar ou não como o processo de integração do recém-migrante ao destino.

Também poder-se-iam elencar outras questões acerca da família e sua articulação com a migração: o status socioeconômico da família e seu ciclo vital (HARBISON, 1981; SCHMINK, 1984); a menor propensão em migrar de famílias compostas por muitos dependentes (HARBISON, 1981; ROOT; DE JONG, 1986); etc.

Já com relação a recursos, trabalhos demonstram que os lares em situações intermédias (financeiramente) são os que possuem maior probabilidade de migrar, haja vista que almejam melhores condições de vida e maiores recursos, ao mesmo tempo em que conseguem acumular o mínimo de capital necessário para efetuar a viagem (DINERMAN, 1978; PESSAR, 1982).

Todavia, há outros tipos de laços e vinculações não unicamente embasados em relações de familiaridade e parentesco que são fundamentais para a completa compreensão da circulação dos recursos e informações no interior da rede, logo, para a compreensão da própria composição da rede. Se até o momento discorremos sobre os ditos "laços fortes" ("strong ties" - tomados como representação dos laços de familiaridade/parentesco), a sua "cara-metade”, ou seja, os laços fracos ("weak ties”) são tão importantes quanto os primeiros (GRANOVETTER, 1973).

Nos estudos migratórios essa diferenciação entre os tipos de vinculação é também recorrente. Laços de amizade e origem comum já são mencionados no estudo de Massey 
et al. (1987). Eles seriam responsáveis pela diminuição dos riscos inerentes à migração, mas essencialmente por meio da disponibilização de recursos imateriais (por exemplo, informações sobre o destino ou sobre possíveis oportunidades de trabalho aí relacionadas).

Outra questão que merece ser considerada neste estudo refere-se ao efeito do tempo de residência sobre o impacto ou importância das redes sociais no processo de assimilação dos migrantes nos locais de origem. De fato, se é verdade que a relação entre migração e redes, como mostramos até agora, é relevante e reconhecida por muitos autores, também deve-se considerar que tal relação não é linear no tempo e nem no espaço.

Como dito, ao menos em nossas buscas bibliográficas, encontramos pouquíssima literatura a respeito da importância das redes sociais sobre os processos migratórios internos, especialmente no caso brasileiro. Obviamente que a incursão em uma bibliografia que trata da migração internacional, fenômeno certamente com outras especificidades, deu-se como forma de buscar elementos que ajudassem a revelar caminhos a partir dos quais a análise das redes poderia contribuir para a melhor compreensão do fenômeno. Assim, se todas as questões consideradas para os fluxos internacionais não se aplicariam à mobilidade residencial interna da população, em particular a intraurbana, não há como negar que várias questões são passíveis de serem incorporadas.

É importante deixar claro que este estudo não tem a pretensão de desenvolver um novo marco teórico que estabeleça uma mediação entre os fatores estruturais que certamente incidem sobre os movimentos migratórios internos e intraurbanos e os motivos destes deslocamentos. Contudo, não há como desconsiderar que os resultados dos estudos para os movimentos internacionais abrem vários caminhos para uma melhor interpretação dos dados. Neste sentido, reconhecer o papel das relações de parentesco, amizade e origem comum, das instituições, etc., para facilitar não apenas o desencadeamento da mobilidade espacial, mas também a fixação e grau de sucesso dos indivíduos e/ou famílias nos locais de destinos, é uma lição aprendida a partir daqueles estudos, sobretudo considerando que, como se poderá mostrar, muitas destas questões também aparecem como relevantes no caso da dinâmica inter e intraurbana.

Assim, tomados os devidos cuidados, paralelos podem ser estabelecidos com movimentos mais locais, tais como os intraurbanos. Por certo, as motivações e os processos que estão por trás das migrações internacionais são muito diferentes daqueles referentes aos movimentos mais regionalmente circunscritos, contudo, as relações sociais estabelecidas ou preexistentes cumprem papel importante em ambos os casos. Basta lembrar o que diziam Duarte et al. (1981) em um dos poucos estudos que tratam da questão: "a grande maioria dos migrantes só se aventura a vir para a metrópole na esteira da experiência de parentes e amigos e que estes são os que resolvem os problemas iniciais de habitação".

Assim como a existência de comunidades ou grupos constituídos nos locais de origem ou a existência de parentes e amigos interferem decisivamente no processo migratório entre países, é possível dizer que efeitos similares podem ser observados no contexto interno de um país ou de uma região. 
Estes “ativos" que podem ser obtidos por meio das redes sociais são também elementos importantes para se avaliar o grau de vulnerabilidade social das pessoas e, especialmente, das famílias nas quais estas se inserem.

Em um texto bastante elucidativo, Kaztman (2000, p. 7, tradução nossa) considera que a vulnerabilidade pode ser entendida como "a incapacidade de uma pessoa ou de um domicílio para aproveitar-se das oportunidades, disponíveis em distintos âmbitos socioeconômicos, para melhorar sua situação de bem-estar ou impedir sua deterioração". Portanto, o autor considera que esta condição seria resultante de uma "defasagem ou falta de sincronia entre os requerimentos de acesso às estruturas de oportunidades oferecidos pelo mercado, Estado e sociedade e os ativos dos domicílios que permitiriam aproveitar estas oportunidades" (KAZTMAN, 2000, p. 2, tradução nossa).

Nesse sentido, o conceito de vulnerabilidade aqui utilizado remete à debilidade ou à força dos ativos que indivíduos ou famílias dispõem para enfrentar os riscos existentes no entorno que implicam a perda de bem-estar (BUSSO, 2001). A ideia, portanto, diria respeito "a um estado dos domicílios que varia em uma relação inversa à sua capacidade para controlar as forças que modelam o seu próprio destino, ou para combater seus efeitos sobre o bem-estar" (KAZTMAN, 2000, p. 2, tradução nossa).

A partir da classificação de ativos proposto por Kaztman (2000), que os divide em termos de três tipos de capitais ("físico/financeiro", "humano" e "social”), percebe-se que os resultados decorrentes das relações sociais podem, em muitos sentidos, se materializar em termos de algum tipo de capital social (ajuda mútua, trocas de favores, ganhos comunitários, informações de várias naturezas, etc.) útil para o enfrentamento de riscos impostos na grande metrópole, sendo o mais geral e indesejado o da pobreza.

É neste sentido que a discussão das redes sociais e migração mais nos interessa neste momento, razão pela qual a identificação de sua ocorrência nas trajetórias das pessoas já nos daria importantes pistas para avaliar seus impactos e consequências sobre suas vidas.

\section{Migração e sua heterogeneidade no espaço metropolitano}

Como dito anteriormente, este trabalho utiliza como fonte de dados uma pesquisa domiciliar amostral realizada em 2007 na Baixada Santista. ${ }^{6}$ Este levantamento permite

\footnotetext{
${ }^{6} 0$ questionário da pesquisa é dividido em uma série de módulos, cada um deles versando sobre uma problemática específica. Desse modo, o produto total é dividido em questões e dados sobre características gerais do domicílio, entorno e percepção ambiental (módulo 1), características sociodemográficas gerais da população (módulo 2), trabalho e rendimentos (módulo 3), mobilidade espacial (módulo 4), família e comunidade (módulo 5), saúde (módulo 6) e, por fim, educação (módulo 7). Em todos os módulos há quesitos que possibilitam, de alguma forma, captar a existência, a atuação e a interação das redes sociais e do capital social com o tema título do módulo. No caso particular dos módulos 2 e 4 é possível obter informações relevantes sobre parte da trajetória migratória de todos os indivíduos dos domicílios. Dados sobre residência anterior, bem como tempo de residência no município, no bairro e no próprio domicílio são algumas das questões presentes. Comparativamente às fontes usuais, como os dados secundários das amostras de Censos Demográficos e PNADs, tais quesitos são enriquecedores para discussão sobre a dinâmica migratória intrametropolitana e reconstrução das trajetórias migratórias desses domicílios e dos seus chefes.
} 
conhecer, entre outras coisas, as características dos movimentos migratórios, tanto na chegada à região metropolitana quanto nos movimentos realizados em nível inter e intramunicipal. Entre os elementos enfatizados, destacam-se a composição sociodemográfica destes migrantes, os motivos da migração, a importância das redes sociais e a aquisição ou perda de capital social.

Para a realização desta pesquisa, foram aplicados perto de 1.600 questionários em uma amostra estratificada de domicílios da região, envolvendo cerca de 4.800 pessoas da Baixada. Os estratos utilizados, aqui chamados de zonas de vulnerabilidade (ZVs), foram obtidos a partir de técnicas estatísticas, ${ }^{7}$ utilizando para tanto o Censo Demográfico de 2000 em nivel de áreas de ponderação (APs).

Ademais, as ZVs (Figura 1) representam grupos homogêneos de APs não apenas do ponto de vista sociodemográfico, mas também quanto ao grau de acesso aos serviços públicos e infraestrutura urbana.

As zonas de vulnerabilidade podem ser descritas da seguinte forma em termos de suas principais características:

- zona de vulnerabilidade do tipo 1 (ZV1) - zona mais periférica, tanto geográfica como socialmente. Do ponto de vista urbano, trata-se de áreas menos consolidadas, além de apresentarem infraestrutura mais deficitária. Sua população possui carências significativas tanto em termos econômicos quanto educacionais, bem como elevado grau de desproteção social;

- zona de vulnerabilidade do tipo 2 (ZV2) - corresponde a uma área intermédia, entre a periferia mais distante e menos valorizada e a orla marítima. É uma zona mais consolidada urbanisticamente em comparação com aquela do tipo 1. Em contraposição, ainda concentra grande parte de seu contingente populacional caracterizado como baixa renda, mas, em relação à zona anteriormente citada, apresenta melhores índices de proteção social;

- zona de vulnerabilidade do tipo 3 (ZV3) - zona mais central, localizada principalmente dentro dos limites municipais de Santos e São Vicente, mais consolidada e, consequentemente, mais valorizada. Esta área abriga população de mais alta renda, além de outras particularidades - domicílios menores, unipessoais e mais envelhecidos.

Antes de prosseguir, é importante frisar que toda a análise aqui realizada não focará a totalidade dos residentes nos domicílios, mas somente o seu responsável para o qual foi levantado um rico conjunto de informações na pesquisa domiciliar que serviu de base empírica.

Tal opção metodológica decorre de um pressuposto básico adotado pela pesquisa e com o qual estamos alinhados: para estudos como os migratórios, a família ${ }^{8}$ deveria ser a unidade

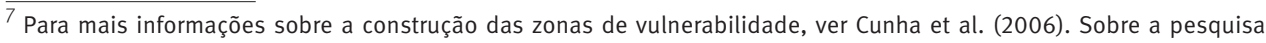
domiciliar, ver Cunha (2008).

${ }^{8}$ Deve-se reconhecer que a família da forma como é definida nos censos e, de maneira geral, nas pesquisas domiciliares não corresponde necessariamente a uma visão que se poderia chamar "sociológica" da mesma. Ainda que as relações de parentesco sejam definidoras dessa categoria na forma de captação, há possibilidades de interpretações errôneas, sobretudo em domicílios com formações mais complexas que o modelo "nuclear" (biparentais ou monoparentais com ou sem filhos). Com isso em mente, o presente projeto deverá ter cuidado ao adotar uma tipologia de família que evite ao máximo tais problemas. Uma delas pode ser encontrada em Bilac (2004).
} 
básica de análise. Ou seja, parte-se da hipótese de que boa parte das decisões, em particular aquelas envolvendo os deslocamentos residenciais, seria tomada no interior da família.

FIGURA 1

Localização das zonas de vulnerabilidade

Região Metropolitana da Baixada Santista - 2007

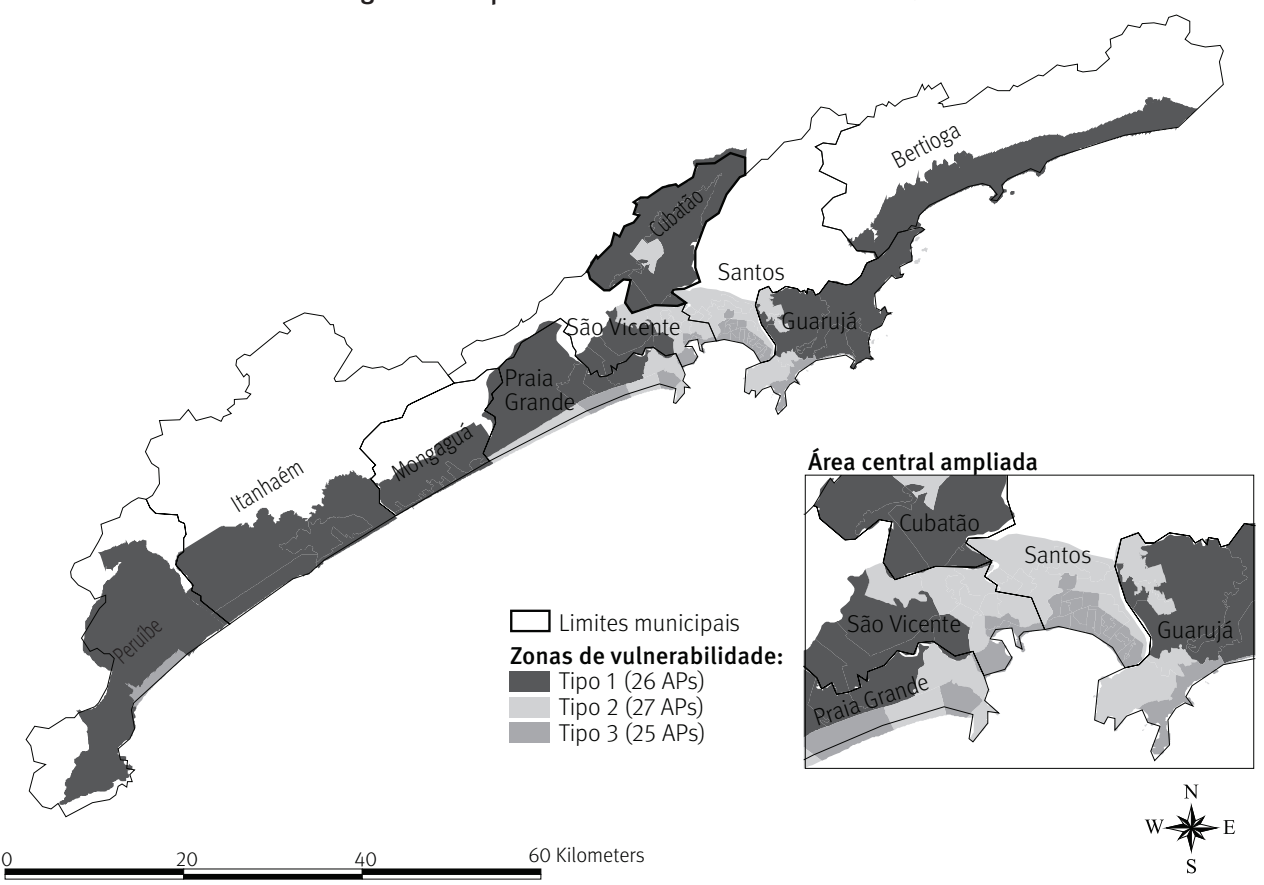

Fonte: Pesquisa domiciliar, Projeto Vulnerabilidade (Fapesp/CNPq), Nepo/Unicamp, 2007.

Em favor de tal opção recorremos às contribuições de alguns autores, ${ }^{9}$ como é o caso de Wood (1982), para quem existe, de certo modo, uma descontinuidade conceitual entre a unidade de análise que deveria ser utilizada para a compreensão do fenômeno (no caso a família) e o movimento migratório propriamente dito (este individual). Da mesma forma, Bilac (1997, p. 177) recupera a importância da família ao considerar que essas são “condicionantes importantes ao longo de todas as etapas do processo migratório: da decisão de morar, dos arranjos econômicos necessários à implementação desta decisão, à integração do migrante à sociedade urbana"; a mesma autora reconhece na família uma importante "esfera da produção e reprodução" dos impactos sofridos por toda e qualquer intempérie socioeconômica (BILAC, 2006, p. 58). Ou seja, não estamos sozinhos ao considerar que as várias características da condição social só podem ser apreendidas com a observação e análise da unidade familiar (PEREIRA, 1999).

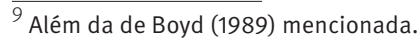


Desta forma, mesmo conscientes de que corremos alguns riscos metodológicos, acreditamos que o uso do responsável do domicílio como uma "proxy" do processo migratório experimentado pela unidade doméstica não representaria grandes perdas em relação ao processo mais geral que se quer estudar. Ao contrário, acreditamos que assim procedendo poderíamos até mesmo evitar certos vieses de interpretação, como fica claro quando a variável "motivo da migração" é analisada e se percebe que a categoria "acompanhar a família" atinge, via de regra, um percentual elevado de respostas.

Talvez um dado contribua para sustentar que o fato de considerarmos apenas os responsáveis não implicaria um viés importante para os resultados: para a Região Metropolitana de Campinas, a mediana da participação dos chefes na renda domiciliar era, em 2007 , superior a $65 \%$, sendo que mais de $45 \%$ destes respondiam por mais de $70 \%$ da renda total. Não negamos que a trajetória migratória familiar tende a ser mais complexa do que a do responsável, mas sustentamos que esta última é central para se compreender parte significativa dessa história. Além disso, o propósito do presente estudo não era quantificar os movimentos migratórios envolvendo a RMBS, o que necessariamente nos obrigaria a tomar toda a população residente, até porque este tipo de objetivo seria temeroso considerando-se o tamanho da amostra recolhida pela pesquisa domiciliar e sua respectiva expansão baseada em projeções demográficas.

Nessa seção, ao menos dois aspectos distintos serão enfatizados como forma de apresentar um pano de fundo para a questão da relação entre a migração e as redes sociais e seus impactos sobre a vida das pessoas: a importância da mobilidade espacial da população na região, vista não só em termos de sua forma mais clássica, ou seja, as mudanças residenciais de caráter inter-regional ou intermunicipal (normalmente considerada migração), mas também em termos de uma modalidade muito menos enfocada nos estudos demográficos, a mobilidade residencial intraurbana. Da mesma forma, serão enfatizadas algumas diferenças entre os migrantes segundo o tempo de residência nos municípios, uma vez que tal variável, como já se fez notar, pode jogar um papel importante nos processos aqui analisados.

Segundo as estimativas populacionais do IBGE, a Região Metropolitana da Baixada Santista possuía, em meados de 2007, cerca de 1.676 mil pessoas vivendo em suas áreas urbanas. Deste volume, os dados da pesquisa mostram que $57,4 \%$ não eram naturais do município de residência. Destes "não naturais", 66,7\% nasceram em outras cidades fora da RMBS, ou seja, o forte peso dos migrantes acumulados (de toda a vida) mostra que se trata de uma região onde a migração historicamente tem tido claro e inequívoco impacto, especialmente nos últimos 30 anos.

As análises aqui apresentadas partem das possíveis diferenças entre dois tipos de migrante. Um dos grupos é delimitado a partir do tempo de residência na região (migrantes de longa data, com mais de dez anos de residência, ou migrantes recentes, com menos de dez anos de residência). Nesse caso, o efeito de "sobrevivência dos mais fortes" (MARTINE, 1980) merece ser levado em consideração. Maya Jariego (2006), em seu estudo sobre as redes sociais de imigrantes, menciona que este fator é central para o desenvolvimento de efetivos 
laços provedores de ajuda e suporte, logo, para a maior ou menor participação/integração social do imigrante à área de destino. Tanto é assim que o percentual de migrantes antigos que não contavam ou não recorriam a ninguém como possível fonte de ajuda financeira é sensivelmente menor em comparação aos migrantes mais recentes. Complementarmente, migrantes antigos tendem a recorrer de forma mais intensa a parentes, possivelmente por terem tido tempo suficiente de tecer redes com esse tipo de vinculação ao longo de sua permanência na metrópole (Tabela 1).

Já em outro artigo (JARIEGO; HOLGADO, 2005), o mesmo autor aponta para outro elemento tão importante quanto o tempo de residência: a própria modalidade migratória. Ou seja, migrantes que se moviam dentro da região possuíam redes sociais mais dispersas neste mesmo território do que aqueles que não se moviam. Uma primeira hipótese é a de que os migrantes intraurbanos, por sua própria experiência migratória pregressa, estão mais fortemente integrados à região do que os migrantes externos, podendo ser menos vulneráveis do que estes justamente por esse motivo. Se tomarmos as relações com vizinhos e amigos como um indicador da heterogeneidade da rede, parece, pelo menos no primeiro momento, que de fato as redes sociais de migrantes intrametropolitanos são mais diversificadas do que aquelas dos migrantes externos (Tabela 2). Parecem, portanto, ser estas interessantes dimensões a serem incluídas no presente estudo.

TABELA 1

Distribuição dos responsáveis pelo domicílio, por tempo de residência, segundo possíveis fontes provedoras de ajuda financeira

Região Metropolitana da Baixada Santista - 2007

Em porcentagem

\begin{tabular}{lccc}
\hline Fontes provedoras de ajuda financeira & 0 a 9 anos & 10 ou mais anos & Não migrante \\
\hline Nenhuma/não recorre & 32,1 & 27,5 & 21,2 \\
Parentes não residentes & 45,8 & 52,5 & 59,5 \\
Parentes moradores da casa & 11,9 & 11,7 & 13,9 \\
Vizinhos/amigos & 10,2 & 8,3 & 5,5 \\
Total (n. abs.) (1) & $\mathbf{7 7 2}$ & $\mathbf{1 . 5 8 2}$ & $\mathbf{2 . 4 0 7}$ \\
\hline
\end{tabular}

Fonte: Pesquisa Domiciliar do Projeto Vulnerabilidade (Fapesp/CNPq). Nepo/Unicamp, 2007.

(1) Não leva em consideração o peso da amostra. Valores não expandidos.

TABELA 2

Distribuição dos responsáveis pelo domicílio, por modalidade migratória, segundo possíveis fontes provedoras de ajuda financeira Região Metropolitana da Baixada Santista - 2007

Em porcentagem

\begin{tabular}{lccc}
\hline Fontes provedoras de ajuda financeira & Intrametropolitano & Externo & Não migrante \\
\hline Nenhuma/não recorre & 29,2 & 28,6 & 20,7 \\
Parentes não residentes & 44,7 & 53,3 & 59,1 \\
Parentes moradores da casa & 14,6 & 10,5 & 15,7 \\
Vizinhos/amigos & 11,5 & 7,6 & 4,5 \\
Total (n. abs.) (1) & $\mathbf{8 1 0}$ & $\mathbf{1 . 5 4 4}$ & $\mathbf{2 . 1 6 6}$ \\
\hline
\end{tabular}

Fonte: Pesquisa Domiciliar do Projeto Vulnerabilidade (Fapesp/CNPq). Nepo/Unicamp, 2007.

(1) Não leva em consideração o peso da amostra. Valores não expandidos. 
Considerando apenas a última origem dos responsáveis por domicílios, ou seja, de todos os indivíduos que residiram em outro município antes daquele onde foram entrevistados, percebe-se que na RMBS 41,4\% dos responsáveis pelos domicílios apresentaram uma residência prévia em outros municípios, contra $22,7 \%$ daqueles que nunca trocaram de município. ${ }^{10}$

Para os migrantes, ou seja, aqueles que declararam município de residência anterior, verifica-se que cerca de dois terços dos responsáveis ${ }^{11}$ pelos domicílios urbanos vieram de fora da Baixada Santista (Gráfico 1). É interessante notar ainda que existem diferenças significativas entre as zonas de vulnerabilidade. De fato, enquanto na ZV3, a mais central e com melhores condições socioeconômicas, é muito maior a importância daqueles provenientes do Estado de São Paulo, o mesmo não se observa na periferia mais distante, onde o peso da migração de última origem dentro da própria região é bem mais elevado. Este resultado reflete, por exemplo, o impacto das transferências de população de mais alta renda da RM de São Paulo para a região, o que acaba gerando intenso fluxo de mobilidade pendular entre as duas áreas (SANTOS, 2008; SILVA, 2009), que são contíguas e, embora separadas pela Serra do Mar, se conectam por um excelente e moderno sistema viário.

Este quadro tende a sofrer alguma alteração quando se consideram apenas os migrantes mais recentes, ou seja, aqueles com menos de dez anos de residência. Nesse caso, de maneira geral, existe um peso relativo maior dos responsáveis provenientes de mais curta distância, com 15,7\% oriundos da sede metropolitana, 20,4\% da própria RM, 13,3\% do Estado de São Paulo e 50,6\% de outros locais. A mudança mais expressiva foi verificada na ZV2, onde houve um aumento substantivo da participação de responsáveis provenientes da sede metropolitana (25,6\%) em detrimento dos locais mais afastados (16,8\%). Como mencionado por outros autores (CUNHA et al., 2006; JAKOB, 2003), isto indica a dinâmica de expansão urbana ainda em curso, com uma migração oriunda da sede e com destino aos seus arredores, ou seja, da ZV3 em direção à ZV2.

Com relação ao número de municípios pelos quais passaram os migrantes antes de chegar ao local de residência no momento da pesquisa, os dados mostram que 54,2\% dos responsáveis vieram diretamente para o município onde residem atualmente. De qualquer maneira, é muito relevante o percentual daqueles com mais de uma etapa migratória (45,8\%).

\footnotetext{
${ }^{10}$ Apenas para se ter uma ideia do que estamos deixando de considerar ao focarmos apenas os responsáveis pelos domicílios, os dados mostram que, do total de residentes na RMBS, 34,4\% apresentaram um município de residência prévia e 43,1\% nunca se moveram. Do total de migrantes, 8,7\% são pessoas menores de 18 anos e 91,3\% maiores de idade, cifras estas que dão a dimensão do que estamos deixando de considerar em termos de trajetórias realmente importantes para se apreender o processo.

${ }^{11}$ Deve-se esclarecer que optou-se por utilizar informação apenas dos responsáveis pelos domicílios visando reduzir o efeito que as crianças que nasceram no local de residência atual possam ter sobre o perfil da migração recebida.
} 
GRÁFICO 1

Distribuição dos migrantes responsáveis por domicílios urbanos, por zonas de vulnerabilidade, segundo local de residência anterior

Região Metropolitana da Baixada Santista - 2007

$\mathrm{Em} \%$

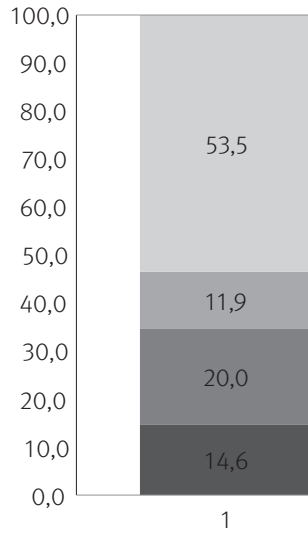

Fora de São Paulo

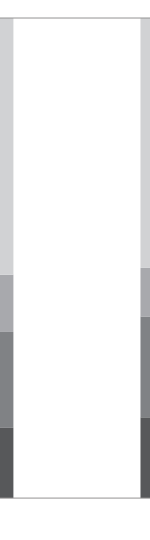

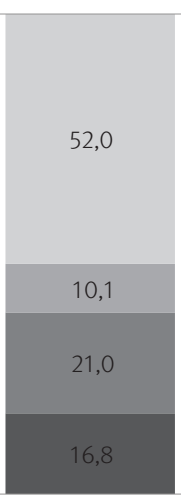

2

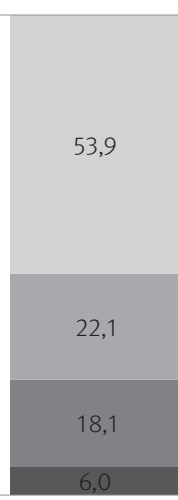

3

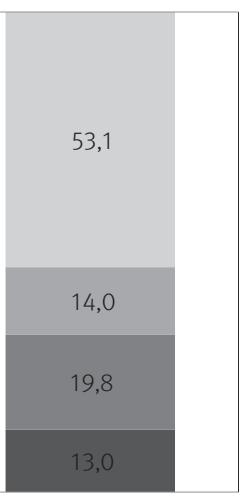

Total RMBS

Zonas de vulnerabilidade

Fonte: Pesquisa domiciliar, Projeto Vulnerabilidade (Fapesp/CNPq), NEPO/UNICAMP, 2007. Nota: Não são considerados os migrantes "sem declaração" de residência anterior.

Uma informação interessante para se entender melhor o processo de ocupação do espaço metropolitano, em geral, e dos municípios, em particular, diz respeito à mobilidade intramunicipal. Esse novo dado levantado pela pesquisa domiciliar (Tabela 3) mostra que, na RM da Baixada Santista, a maior parte dos migrantes responsáveis pelos domicílios realizou três ou mais mudanças dentro do município de residência atual (32,6\%), fato que revela a intensidade da mobilidade intraurbana. Seguem, em importância, aqueles chefes que nunca se moveram $(28,3 \%)$ e os que realizaram duas mudanças $(23,6 \%)$.

TABELA 3

Distribuição dos migrantes responsáveis por domicílios urbanos, por zonas de vulnerabilidade, segundo número de mudanças intramunicipais

Região Metropolitana da Baixada Santista - 2007

Em porcentagem

\begin{tabular}{lcccc}
\hline \multirow{2}{*}{ Número de mudanças } & \multicolumn{3}{c}{ Zonas de vulnerabilidade } \\
\cline { 2 - 5 } & $\mathbf{1}$ & $\mathbf{2}$ & $\mathbf{3}$ & Total RMBS \\
\hline Nenhuma & 32,3 & 27,0 & 24,7 & 28,3 \\
1 & 15,7 & 13,0 & 11,5 & 13,6 \\
2 & 24,6 & 27,7 & 18,3 & 23,6 \\
3 ou mais & 26,3 & 29,3 & 44,1 & 32,6 \\
Sem declaração & 1,1 & 3,0 & 1,5 & 1,8 \\
Total (n. abs.) (1) & $\mathbf{5 4 2}$ & $\mathbf{5 1 5}$ & $\mathbf{5 3 8}$ & $\mathbf{1 . 5 9 5}$ \\
\hline
\end{tabular}

Fonte: Pesquisa domiciliar, Projeto Vulnerabilidade (Fapesp/CNPq), Nepo/Unicamp, 2007.

(1) Não leva em consideração o peso da amostra. Valores não expandidos. 
Este dado torna-se ainda mais interessante se observado a partir das zonas de vulnerabilidade. Assim, enquanto as ZVs 1 e 2 apresentam um perfil parecido com o do total da região, a ZV3 registra uma participação muito maior dos responsáveis com três mudanças ou mais (44\%). Este dado sugere que a população menos vulnerável e em melhores condições socioeconômicas, embora apresente menor mobilidade intrametropolitana, tem maior tendência a mudanças dentro do próprio município, fato que se mostra coerente com as maiores possibilidades de escolha em comparação com os estratos mais baixos.

\section{Por que migram as pessoas?}

Como se pode observar a partir das informações coletadas, os motivos ${ }^{12}$ externados pelas pessoas para migrarem variam significativamente segundo a modalidade do movimento realizado: inter ou intra-regional. Da análise destes dados pode-se inferir sobre os condicionantes mais profundos que levam as pessoas ou grupos de pessoas a decidirem pela migração. Cunha (1994) discute dois principais motivos associados à migração intrametropolitana da RMSP: o mercado de trabalho e o habitacional. Jakob (2003), ao abordar especificamente a RMBS, descreve o processo de expansão urbana por meio do extravasamento populacional do seu município-sede (já saturado devido aos seus condicionantes físico-territoriais). Assim, embora não seja o objeto central do presente texto, é interessante notar que as questões relativas ao mercado de trabalho e mercado de terra seriam essenciais para se compreender em sua plenitude parte significativa dos movimentos migratórios envolvendo a RMBS.

De maneira geral, as motivações predominantes para escolher tanto a RMBS quanto um município metropolitano em particular são as mesmas (Gráfico 2). No entanto, é facilmente observado que, no primeiro caso, o fator trabalho mostra-se muito mais importante, sendo o motivo externado por cerca de $32 \%$ do responsáveis por domicílios. Já no segundo caso, ou seja, na escolha do município, parecem pesar outros elementos em particular - o que seria de se esperar -, como a busca por moradia. Ou seja, como mencionado anteriormente, percebe-se que os condicionantes dos processos migratórios variam significativamente de acordo com a modalidade dos movimentos.

De fato, como assinalado, o significativo volume da migração intrametropolitana por motivação habitacional, em geral influenciado pelas dificuldades dos estratos mais pobres de permanecer nas áreas mais valorizadas, acaba prevalecendo, ou, como é aqui o caso, se equiparando com o motivo trabalho. De qualquer maneira, tendo em vista que a migração direta para os locais de residência atual é também importante na região, a questão de busca por trabalho não deixa de se constituir na de maior percentual, inclusive no caso da migração para o município.

\footnotetext{
12 Da mesma forma como Singer o faz, distinguimos os motivos (pessoais) das causas (estruturais ou mesmo conjunturais) de migração. Assim procedemos para não deixar dúvidas de que, para o cabal entendimento do processo migratório, é fundamental que se conheçam e se aprofundem os fatores que levam grupos populacionais - e não apenas indivíduos isolados - sociais a se movimentarem.
} 
Vale lembrar ainda que o importante percentual alcançado pelo motivo "acompanhar a família” está em boa medida ligado ao fato de estes responsáveis terem migrado ainda muito jovens com sua família original. De fato os dados da pesquisa mostram que, entre os responsáveis que declararam tal motivo, 95\% possuíam no momento de pesquisa um tempo de residência superior a dez anos e 78,6\% residiam há mais de 20 anos na localidade, fato que permite inferir que, no momento da migração, estas pessoas eram ainda crianças ou adolescentes, uma vez que a idade mediana dos migrantes responsáveis por domicílios na pesquisa era de 51 anos.

\section{GRÁFICO 2}

\section{Distribuição dos migrantes responsáveis por domicílios urbanos, segundo principais motivos para migrarem para região e o município Região Metropolitana da Baixada Santista - 2007}

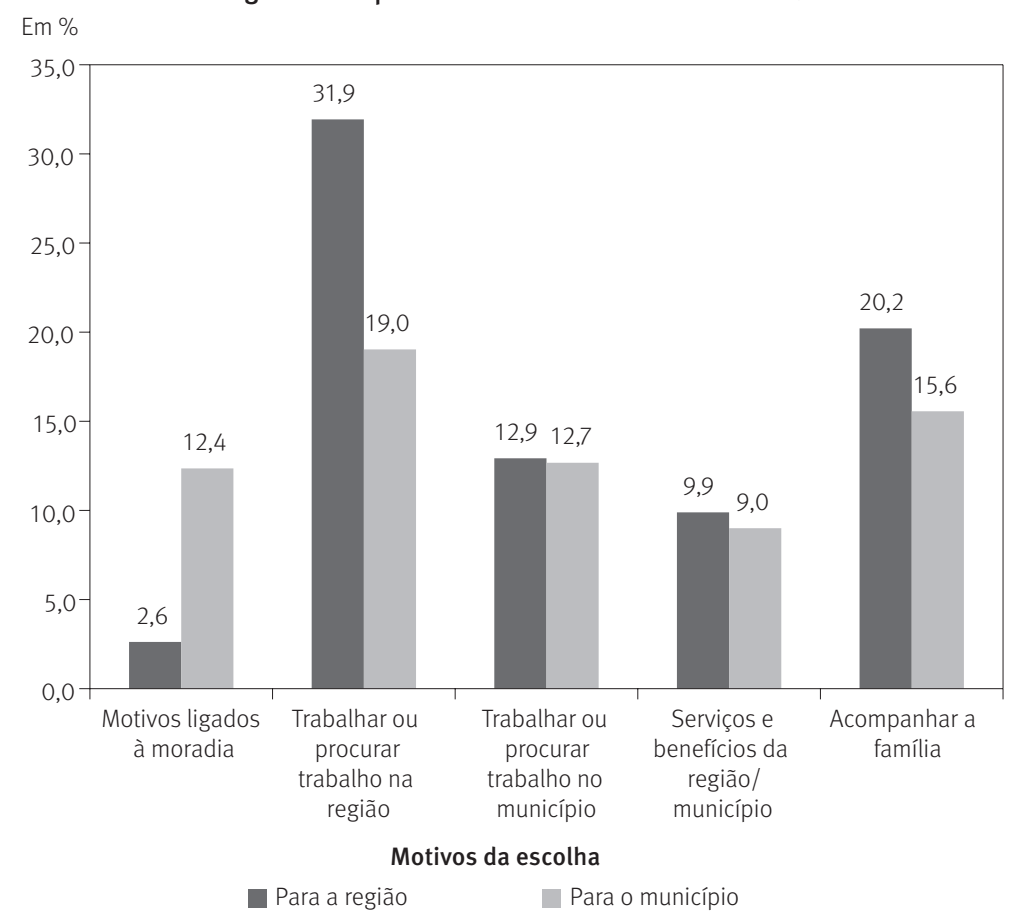

Fonte: Pesquisa domiciliar, Projeto Vulnerabilidade (Fapesp/CNPq), Nepo/Unicamp, 2007.

Em termos das zonas de vulnerabilidade, observa-se que o motivo "trabalho" é muito mais significativo na ZV1, onde vivem as pessoas de mais baixa renda, sendo que nas zonas com menor grau de vulnerabilidade outros motivos afloram como importantes, como é o caso da busca por "serviços", que motivou a mudança para a ZV3 de quase um quinto dos migrantes responsáveis por domicílio ali residentes. Esse fato também se mostra coerente com as características da região e, particularmente, com áreas onde se localizam estas pessoas, ou seja, locais próximos à orla, com óbvias amenidades e com um importante complexo de serviços a oferecer (por exemplo, para as pessoas mais idosas). 
O quadro de motivações da migração fica ainda mais claro quando se observam os motivos que levaram os migrantes a deixarem seus municípios de residência anterior. Nesse caso, três motivações cercam a maior parte daqueles que migraram: as ligadas ao trabalho (34,2\%); os problemas de moradia (32,2\%); e a necessidade de acompanhar a família (17,4\%) (Gráfico 3). Nesse último caso, como assinalado anteriormente, há que se relativizar o resultado, uma vez que grande parte é composta por pessoas que migraram com seus pais ou familiares quando ainda jovens. Já no que se refere às duas primeiras motivações, os dados dão conta de que aquelas relacionadas ao trabalho são bem mais frequentes para os migrantes que chegam diretamente de áreas externas à RM (cerca de 44\%), enquanto as ligadas à habitação são externadas por $50 \%$ do migrantes que fizeram um movimento intrametropolitano. Salienta-se que esse padrão de motivações foi também identificado no caso das motivações que levaram à escolha da região e do município de residência no momento da entrevista.

GRÁFICO 3

Distribuição dos migrantes responsáveis por domicílios urbanos, por zonas de vulnerabilidade, segundo principais motivos da saída do município anterior Região Metropolitana da Baixada Santista - 2007

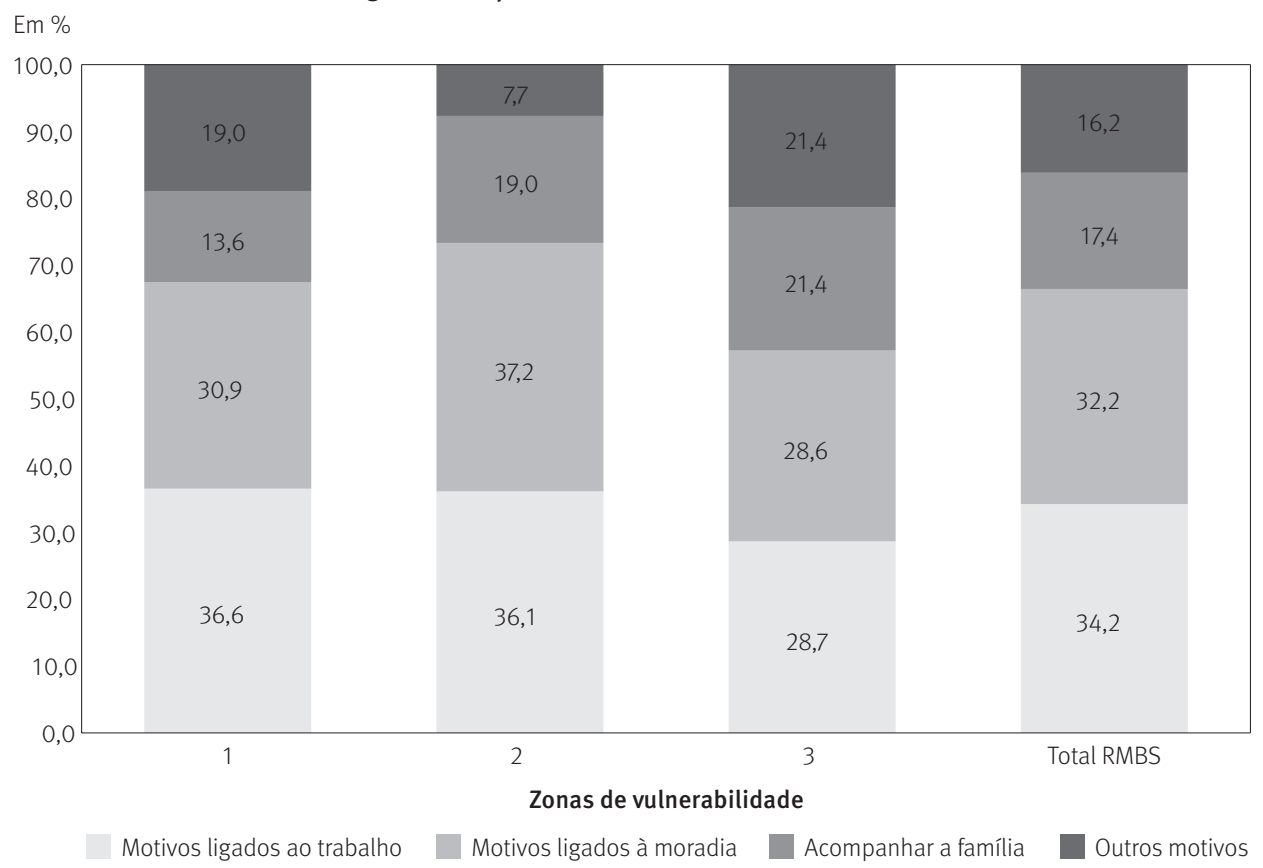

Fonte: Pesquisa domiciliar, Projeto Vulnerabilidade (Fapesp/CNPq), Nepo/Unicamp, 2007.

Segundo as zonas de vulnerabilidade, novamente percebe-se que a questão do trabalho é muito mais importante na ZV1 do que na ZV3, mostrando que este é, sem dúvida, um elemento central para diferenciar a migração dos distintos grupos sociais. Por outro lado, a insatisfação com a moradia e o trabalho parece afetar a decisão migratória com maior intensidade para aqueles que residem nas zonas de menor vulnerabilidade, fato que reforça conclusões de outros estudos que sugerem que a RMBS tem papel importante no processo 
migratório das classes mais abastadas, particularmente aquelas provenientes da Região Metropolitana de São Paulo, que buscam lugares mais tranquilos e aprazíveis para morar (SANTOS, 2008; YOUNG; SANTOS, 2008).

\section{Migração e redes sociais: evidências empíricas sobre sua importância para a mobilidade territorial}

Mesmo considerando que, como mostrado anteriormente, os motivos de migração estejam sempre ligados a questões econômicas ou mesmo à habitacional, com variações significativas segundo as modalidades de movimentos, é necessário levar em conta que as redes sociais podem ter papel importante no entendimento do processo migratório, pois, a partir delas, é possível que os fluxos, uma vez desencadeados, ganhem força, redirecionemse ou mesmo se interrompam.

Efetivamente, não apenas o suporte material que pode ser prestado por parentes, amigos ou conterrâneos, mas também as informações decorrentes destas relações podem ser relevantes elementos, se não para explicar os movimentos migratórios, cujos condicionantes são na verdade muito mais complexos, ao menos para ajudar a compreender certas características, ou mesmo consequências do processo migratório.

No que diz respeito à migração interna, especialmente aquela observada nas maiores aglomerações urbanas, o reconhecimento da ação (ou não) das redes pode ajudar a compreender alguns fluxos estabelecidos e também as consequências da mobilidade espacial sobre as condições de vida e vulnerabilidade de certas famílias ou pessoas. De fato, como sustentam Kaztman et al. (1999), a mobilidade ou a possibilidade desta pode ser entendida como um ativo que permitiria, ao menos em algumas dimensões da vida - por exemplo, a habitação -, a redução do grau de vulnerabilidade de indivíduos. No entanto, os mesmos autores reconhecem que a migração pode também afetar a disponibilidade de capital social e informações quando esta se dá de um local conhecido para outro parcialmente desconhecido.

Ou seja, apesar de bastante variável em termos do seu impacto, a ação das redes sociais pode ter influência decisiva sobre a vida das pessoas, particularmente dos migrantes recentes, que provavelmente seriam mais vulneráveis em nossas grandes cidades, tanto por sua condição econômica normalmente desfavorável, quanto pela menor informação e conhecimento sobre as oportunidades aí existentes em termos de mercado de trabalho e de terras.

Embora não seja intenção desse estudo realizar uma análise exaustiva destas consequências, pretende-se ao menos mostrar a realidade e importância desse fenômeno no contexto de uma das três RMs do Estado de São Paulo.

Um dos primeiros aspectos que podem revelar a ação das redes sociais diz respeito à forma de inserção residencial do indivíduo na sua chegada a uma região. As redes, nesse sentido, poderiam funcionar como pontes, principalmente quando há contatos 
preexistentes nas áreas de destino. Com isso, o processo de integração do migrante à região seria facilitado, haja vista que pelo menos um dos riscos (e também custos) inerentes à migração - no caso, oportunidades de moradia/habitação no momento de chegada à região - seria minimizado.

A Tabela 4 fornece esse tipo de informação, ao trazer o local de moradia dos responsáveis por domicílio quando chegaram à Baixada Santista. Assim, percebe-se que, muito embora a maioria destes migrantes tenha vindo para morar em domicílios alugados (38,8\%) ou próprios (27,3\%), é muito significativa a parcela dos responsáveis que chegaram à região para morar em casa de parentes (perto de 20\%) e também não é desprezível o percentual de chefes que se instalaram em casas cedidas (5,5\%). O interessante a notar é que a importância destas duas práticas é ainda maior na ZV1 (cerca de 26\% e 8\%, respectivamente).

Neste caso fica muito claro que o apoio de parentes é um expediente bem mais comum, especialmente nas áreas mais carentes da região, aqui representadas pela ZV1. Mesmo em situações de “áreas de ocupação”, que para a ZV1 representa quase dez vezes o observado nas demais zonas, é muito provável que esta prática seja, em boa medida, favorecida pela ação das redes sociais.

TABELA 4

Distribuição dos migrantes responsáveis por domicílios urbanos, por zonas de vulnerabilidade, segundo tipo de moradia ao chegar à região

Região Metropolitana da Baixada Santista - 2007

Em porcentagem

\begin{tabular}{lcccc}
\hline \multirow{2}{*}{$\begin{array}{c}\text { Tipo de moradia ao } \\
\text { chegar à região }\end{array}$} & \multicolumn{4}{c}{ Zonas de vulnerabilidade } \\
\cline { 2 - 5 } & $\mathbf{1}$ & $\mathbf{2}$ & $\mathbf{3}$ & Total RMBS \\
\hline Casa própria & 20,0 & 24,3 & 40,5 & 27,3 \\
Casa alugada & 31,8 & 49,0 & 37,8 & 38,8 \\
Casa de parentes & 25,8 & 16,3 & 15,1 & 19,8 \\
Casa cedida & 8,2 & 4,1 & 3,3 & 5,5 \\
Área de ocupação & 10,0 & 2,0 & 0,4 & 4,7 \\
Outros & 4,1 & 4,4 & 2,9 & 3,9 \\
Total (n. abs.) (1) & $\mathbf{3 2 9}$ & $\mathbf{2 9 2}$ & $\mathbf{2 9 8}$ & $\mathbf{9 1 9}$ \\
\hline
\end{tabular}

Fonte: Pesquisa domiciliar, Projeto Vulnerabilidade (Fapesp/CNPq), Nepo/Unicamp, 2007.

(1) Não leva em consideração o peso da amostra. Valores não expandidos.

São dignos de nota também os percentuais obtidos pelas opções “casa própria”, no caso dos migrantes que residem na ZV3, e "casa alugada”, para os moradores na ZV2, estratégias que se mostram condizentes com os maiores níveis socioeconômicos e grau de consolidação urbana destas áreas. Embora não se possa afirmar que para os estratos mais altos a ação das redes não tenha sido importante, não é difícil imaginar que estas terão bem menos impacto do que para os mais necessitados. Na verdade, tal afirmação, mesmo não sendo confirmada em absoluto por meio dos dados aqui utilizados, encontra certo respaldo no trabalho de Marques (2010). O autor descreve que os indivíduos em situação de pobreza são mais dependentes de suas redes sociais do que aqueles provenientes de estratos mais 
abastados, afinal estes últimos, por sua própria condição econômico-financeira, conseguem apelar para outras esferas, tais como o próprio mercado. Evidencia-se com estes dados, portanto, a maior importância de elementos de capital social no processo migratório das pessoas que se dirigem para áreas mais vulneráveis da região.

Outra maneira de aquilatar o papel das redes sociais no processo migratório regional é conhecer a forma como os migrantes obtiveram informações sobre a área (Tabela 5). Assim, percebe-se que quase $60 \%$ dos migrantes responsáveis por domicílio inteiraram-se sobre a região por meio de parentes e amigos, o que demonstra a importância dessas relações, se não para o desencadeamento dos fluxos migratórios nas origens, ao menos para o seu direcionamento. Sobre o comportamento desta variável nas zonas de vulnerabilidade, verificase que, na ZV3, ou seja, a menos vulnerável, a importância de informações de parentes e amigos é bem menos relevante, sendo o conhecimento prévio da região bem mais presente nos residentes destas áreas.

TABELA 5

Distribuição dos migrantes responsáveis por domicílios urbanos, por zonas de vulnerabilidade, segundo formas de obtenção de informações sobre a região Região Metropolitana da Baixada Santista - 2007

\begin{tabular}{lrrrr} 
& & \multicolumn{3}{c}{ Em porcentagem } \\
\hline \multirow{2}{*}{ Formas de obtenção de informações } & \multicolumn{3}{c}{ Zonas de vulnerabilidade } \\
\cline { 2 - 5 } & $\mathbf{1}$ & $\mathbf{2}$ & $\mathbf{3}$ & Total RMBS \\
\hline Informações de parentes ou amigos & 65,3 & 64,4 & 39,6 & 57,5 \\
Ouviu falar no município onde residia & 7,5 & 9,2 & 10,9 & 9,0 \\
Já conhecia o município & 23,3 & 19,1 & 45,3 & 28,4 \\
Outra forma & 3,9 & 7,4 & 4,3 & 5,1 \\
Total (n. abs.) (1) & $\mathbf{3 3 2}$ & $\mathbf{2 9 4}$ & $\mathbf{2 9 8}$ & $\mathbf{9 2 4}$ \\
\hline
\end{tabular}

Fonte: Pesquisa domiciliar, Projeto Vulnerabilidade (Fapesp/CNPq), Nepo/Unicamp, 2007.

(1) Não leva em consideração o peso da amostra. Valores não expandidos.

Parentes e amigos também constituem importantes fontes de informações sobre o bairro onde residiam os migrantes responsáveis por domicílio no momento de pesquisa. De fato, quase $64 \%$ deles declararam haver consultado estes contatos a respeito do local onde residiam (Gráfico 4), o que reforça o peso das redes sociais também para a mobilidade intramunicipal. Vale ressaltar que a importância deste tipo de mobilidade é expressa pela baixa proporção (22\%) de responsáveis pelo domicílio que nasceram no bairro onde foram entrevistados.

Percebe-se ainda que, no caso da escolha e obtenção das informações sobre o bairro, o leque de alternativas é um pouco maior, pois cerca de 15\% dos migrantes responsáveis por domicílio declararam outra forma de obtenção de informações, como experiência prévia no bairro ou por meio de propagandas e organizações sindicais. Aqui as diferenças entre as ZVs são muito menos aparentes, embora a ZV3 continue apresentando um perfil de resposta um pouco distinto em relação às demais. 
GRÁFICO 4

Distribuição dos migrantes responsáveis por domicílios urbanos, por zonas de vulnerabilidade, segundo formas de obtenção de informações sobre o bairro

Região Metropolitana da Baixada Santista - 2007

$\mathrm{Em} \%$

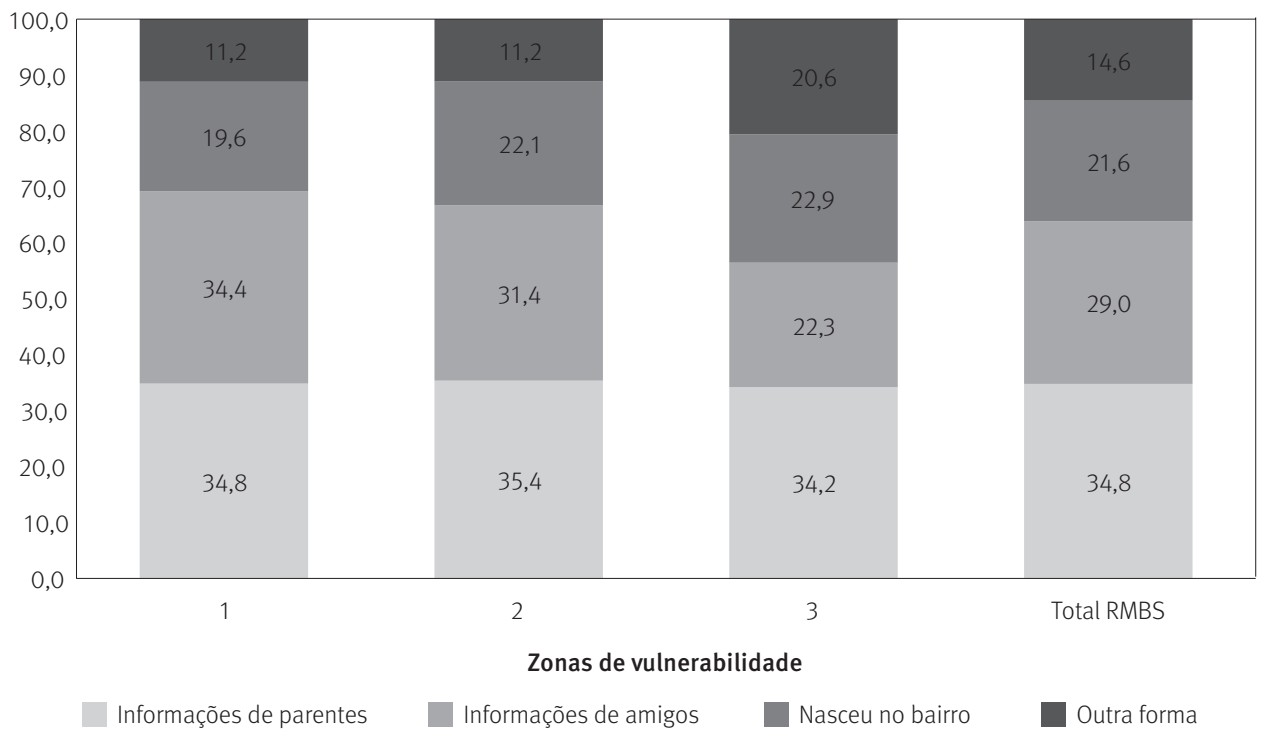

Fonte: Pesquisa domiciliar, Projeto Vulnerabilidade (Fapesp/CNPq), Nepo/Unicamp, 2007.

A migração, além de ser uma estratégia adotada para solucionar ou remediar possíveis carências em oportunidades de emprego ou moradia, pode também ter papel significativo na alteração das relações sociais e da rede de apoio daqueles que migram, provocando impactos sobre a vulnerabilidade destas pessoas. A migração, nesse sentido, poderia funcionar como "uma faca de dois gumes": ao mesmo tempo em que possibilitaria a construção de novos contatos (talvez mais diversificados entre si), poderia também romper contatos preexistentes. Ou seja, determinados recursos poderiam momentaneamente deixar de fluir no interior da rede social do migrante, empurrando-o para situações mais vulneráveis quando comparado àqueles que não migraram.

Ao que tudo indica, a migração parece reforçar as relações e rede de parentesco, pois mais de $41 \%$ dos migrantes responsáveis por domicílios urbanos afirmaram que suas possibilidades de contar com a ajuda de parentes aumentaram a partir da mudança de residência (Gráfico 5). O mesmo não pode ser dito sobre as relações com amigos e vizinhos, uma vez que, nos dois casos, para a maioria dos respondentes, estas permaneceram inalteradas (68,3\% e 75,8\%, respectivamente). Mas é possível observar que, mesmo nessa situação, a migração não teria efeitos deletérios sobre as relações sociais das pessoas. De qualquer maneira, é significativa a proporção de migrantes que declararam ter incrementado suas possibilidades de contar com a ajuda de amigos e vizinhos a partir do movimento. 


\section{GRÁFICO 5}

Distribuição dos migrantes responsáveis por domicílios urbanos, segundo implicações da migração intermunicipal nas possibilidades de contar com ajuda de parentes, amigos e vizinhos Região Metropolitana da Baixada Santista - 2007

$\mathrm{Em} \%$

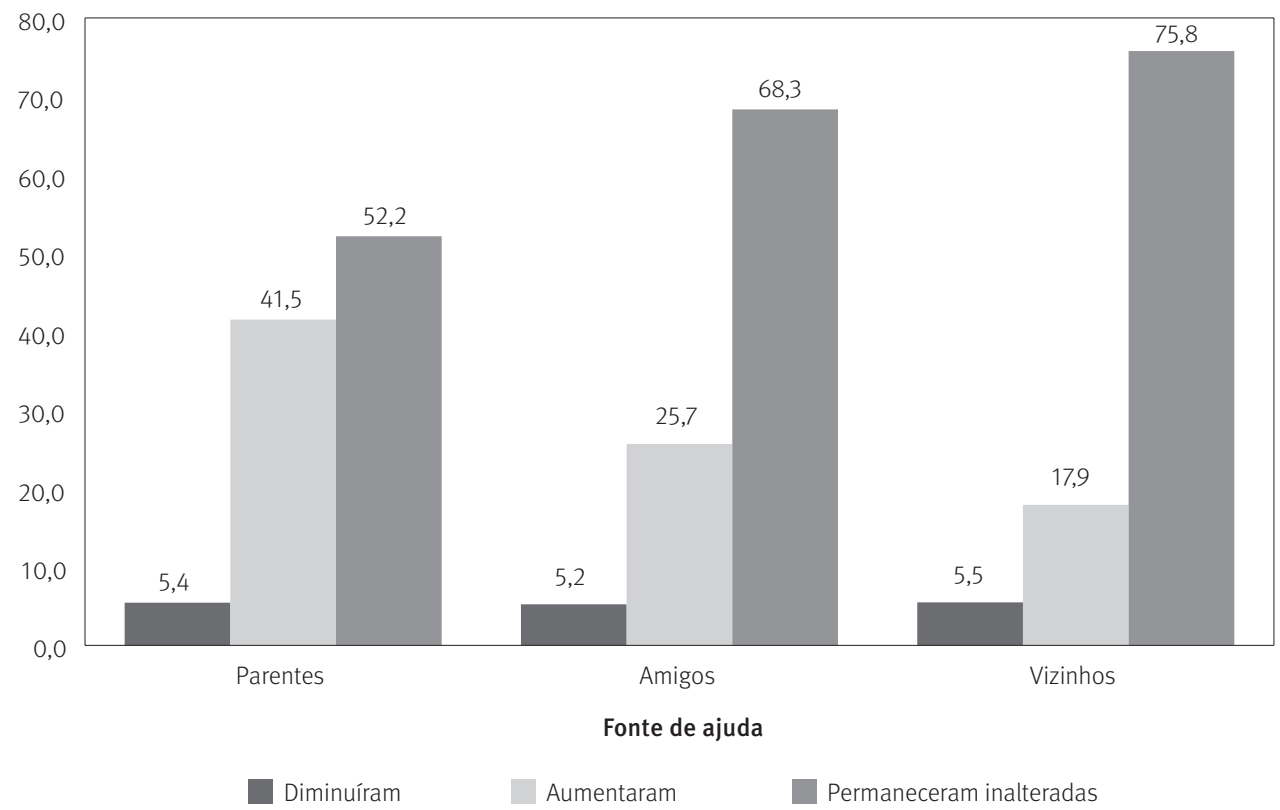

Fonte: Pesquisa domiciliar, Projeto Vulnerabilidade (Fapesp/CNPq), Nepo/Unicamp - 2007.

Nota: Não estão incluídos aqueles que não souberam informar sobre a fonte de ajuda.

Destaca-se, ainda, a baixa proporção de respostas na categoria “ diminuíram”, demonstrando que, ao menos para os migrantes da RMBS, a migração acabou sendo um mecanismo de aquisição de capital social. Do ponto de vista das zonas de vulnerabilidade, percebe-se que os migrantes residentes nas áreas mais vulneráveis da região (ZV1) aparentam ter obtido maiores ganhos em suas relações sociais (principalmente aquelas embasadas em laços de parentesco), especialmente porque, para quase $60 \%$ deles, houve aumento na possibilidade de contar com a ajuda de parentes. De fato, é nessa zona onde se encontra a menor proporção de respostas "permaneceram inalteradas".

Na verdade deve-se considerar que, tendo em vista a maior precariedade das condições médias de vida e de habitação da ZV1, é no mínimo alvissareiro o fato de as pessoas declararem ter melhorado sua rede de apoio, pois isto pode constituir-se em potencial ativo para a redução de suas vulnerabilidades, ainda que em regiões com infraestrutura e serviços em condições mais adversas.

\section{Considerações finais}

Este trabalho procurou abordar a migração como elemento central no processo de expansão urbana de uma importante aglomeração urbana, no caso a RM da Baixada Santista, 
e a sua relação com as redes sociais estabelecidas pelos atores envolvidos, no sentido de perceber como estas últimas trabalham não apenas enquanto elemento de estruturação dos fluxos migratórios, mas, sobretudo, como forma de aquisição de capital social, visando a redução da vulnerabilidade das pessoas e famílias.

Para tanto, lançou-se mão de um levantamento domiciliar inédito realizado na Baixada Santista, cujas informações recolhidas possibilitaram, por suas especificidades, uma análise diferenciada da questão.

Como discutido ao longo deste trabalho, a migração, em suas várias modalidades, mesmo sendo reflexo de processos estruturais mais amplos e motivada por busca de soluções para problemas de emprego, condições habitacionais, etc., também pode ser, por um lado, considerada elemento fundamental na modificação das relações sociais e, por outro, facilitada ou constrangida por estas.

Na verdade, os dados apresentados neste estudo, além de fornecerem uma visão geral sobre a mobilidade residencial em suas diferentes escalas espaciais, bem como motivações, sugerem algumas das relações possíveis estabelecidas entre o fenômeno migratório e as redes sociais estabelecidas ou dissolvidas neste processo.

Os resultados sugerem que a migração parece reforçar, sobretudo, as relações e a rede de parentesco, quando mostram que mais de $41 \%$ dos migrantes responsáveis por domicílios urbanos perceberam incremento nas suas possibilidades de contar com a ajuda de parentes a partir da mudança de residência e pouquíssimos declararam que estas tenham se deteriorado.

Outra conclusão permitida pelo estudo diz respeito ao fato de que, em termos do local de moradia da população, representadas aqui pelas zonas de vulnerabilidade, os migrantes residentes em áreas mais periféricas e mais vulneráveis, como a ZV1, parecem ter conseguido maiores ganhos em suas relações sociais, uma vez que, para $60 \%$ deles, a possibilidade de contar com a ajuda de parentes aumentou com a migração. Esta constatação é de fundamental importância, pois sugere que, mesmo residindo em áreas mais carentes de infraestrutura e serviços, os migrantes podem ver esta adversidade em parte compensada por outros tipos de ativos (não tangíveis), contribuindo para a redução de suas vulnerabilidades.

Mesmo reconhecendo que a questão da vulnerabilidade social das famílias e indivíduos somente poderá ser completamente solucionada com a inserção real, definitiva e, mais que isso, não precária destas pessoas no mercado de trabalho e consumo, bem como com o seu acesso aos serviços e infraestrutura básicos, é relevante constatar que o papel do capital social não deve ser negligenciado.

Assim, além de contribuir nesta direção, espera-se que este estudo também tenha podido motivar outras incursões analíticas que relacionem redes sociais com movimentos migratórios, considerando a carência deste tipo de enfoque, principalmente, para as escalas mais regionais ou locais, fato que tem limitado a análise dos processos de expansão urbana dos municípios e regiões metropolitanas do país. 


\section{Referências}

BAENINGER, R. Reestruturação urbana: algumas considerações sobre o debate atual. Campinas: Nepo/Unicamp, 2000.

BILAC, E.; D. Gênero, vulnerabilidade das famílias e capital social. In: CUNHA, J. M. P. (Org.). Novas metrópoles paulistas: população, vulnerabilidade e segregação. Campinas: Nepo/Unicamp, 2006.

Arranjos domésticos e condição migratória. In: PATARRA, N. et al. (Orgs.). Migração, condições de vida e dinâmica urbana: São Paulo 1980-1993. Campinas: Unicamp/IE, 1997.

BORJAS, G. J. Friends or strangers: the impact of immigrants on the U.S. economy. Nova York: Basic Books, 1990.

BOTT, E. Family and social networks. London: Tavistock, 1957.

BOYD, M. Family and personal networks in international migration: recent developments and new agendas. International Migration Review, v. XXIII, n. 3, 1989.

BUSSO, G. La vulnerabilidad social y las políticas sociales a inícios del siglo XXI: una aproximación a sus potencialidades y limitaciones para los países latinoamericanos. Santiago do Chile: Cepal/Celade, 2001.

CUNHA, J. M. P. (Org.). Novas metrópoles paulistas: população, vulnerabilidade e segregação. Campinas: Núcleo de Estudos de População/Unicamp, 2006.

Mobilidade populacional e expansão urbana: o caso da Região Metropolitana de São Paulo. Tese (Doutorado em Ciências Sociais), Instituto de Filosofia e Ciências Humanas-Unicamp, Campinas, 1994.

. (Org.). Sumário de dados da Região Metropolitana da Baixada Santista. Campinas: Nepo/Unicamp, 2008. Disponível em: 〈http://www.nepo.unicamp.br/vulnerabilidade/sumario/ sumario_final_RMBS/index.html>.

CUNHA, J. M. P.; JAKOB, A. A. E.; YOUNG, A. F. Dinâmica demográfica intrametropolitana na Região Metropolitana da Baixada Santista, no período pós-1970. In: CUNHA, J. M. P. (Org.). Novas metrópoles paulistas: população, vulnerabilidade e segregação. Campinas: Núcleo de Estudos de População/ Unicamp, 2006.

CUNHA, J. M. P. et al. A vulnerabilidade social no contexto metropolitano: o caso de Campinas. In: CUNHA, J. M. P. (Org.). Novas metrópoles paulistas: população, vulnerabilidade e segregação. Campinas: Nepo/Unicamp, 2006.

CUNHA, T. A. Redes sociais, capital social e mobilidade residencial intrametropolitana: o caso da Região Metropolitana da Baixada Santista. Dissertação (Mestrado em Demografia) - Instituto de Filosofia e Ciências Humanas, Unicamp, Campinas, 2010.

DINERMAN, I. R. Patterns of adaptation among households of U.S. - Bound migrants from Michoacan, Mexico. International Migration Review, v. XII, n. 4, 1978.

DUARTE, J. C. (Coord.). Migrações intrametropolitanas, reprodução da força de trabalho e formação da periferia de São Paulo. São Paulo: Prodeur/FAU, USP, 1981. Mimeografado.

FAZITO, D. A. R. Reflexões sobre os sistemas de migração internacional: proposta para uma análise estrutural dos mecanismos intermediários. Tese (Doutorado em Demografia) - Centro de Desenvolvimento e Planejamento Regional, Universidade Federal de Minas Gerias, Belo Horizonte, 2005.

FUSCO, W. Capital social e dinâmica migratória: um estudo sobre brasileiros nos Estados Unidos. Campinas: Núcleo de Estudos de População/Unicamp, 2007 (Textos Nepo, 52). 
Redes sociais na migração internacional: o caso de Governador Valadares. Campinas: Núcleo de Estudos de População/Unicamp, 2002 (Textos Nepo, 30).

GRANOVETTER, M. S. The strength of weak ties. American Journal of Sociology, v. 78, n. 6, 1973.

HANNEMAN, R.; RIDDLE, M. Introduction to social network methods. Riverside, CA: University of California, 2005. Disponível em: 〈http://wizard.ucr.edu/ rhannema/index.html\#news〉. Acesso em: 21 jun. 2010.

HARBISON, S. F. Family structure and family strategy in migration decision making. Migration decision making: multidisciplinary approaches to microlevel studies in developed and developing countries. Nova York: Pergamon Press, 1981.

HIRANO, F. Y. O caminho para casa: o retorno dos dekasseguis. Campinas: Núcleo de Estudos de População/Unicamp, 2008 (Textos Nepo, 54).

JAKOB, A. A. E. Análise sócio-demográfica da constituição do espaço urbano da Região Metropolitana da Baixada Santista no período 1960-2000. Tese (Doutorado) - IFCH/Unicamp, Campinas, 2003.

JAKOB, A. A. E.; CUNHA, J. M. P.; YOUNG, A. F. Riqueza à beira-mar, pobreza longe da maresia: um retrato da segregação social na Região Metropolitana da Baixada Santista, nos anos 1990. In: CUNHA, J. M. P. (Org.). Novas metrópoles paulistas: população, vulnerabilidade e segregação. Campinas: Núcleo de Estudos de População/Unicamp, 2006.

JARIEGO, I. M. Webs of compatriots: relationship networks among immigrants. In: PÉREZ PONT, J. L. (Ed.). Geografías del desorden. Migración, alteridad y nueva esfera social. Valencia: Universidad de Valencia, 2006, p. 651-665.

JARIEGO, I. M.; HOLGADO, D. Lazos fuertes y proveedores múltiples de apoyo: comparación de formas de representación gráfica de las redes personales. Empiria. Revista de Metodología de Ciencias Sociales, v. 10, p. 107-127, 2005.

KAZTMAN, R. et al. Vulnerabilidad, activos y exclusión social en Argentina y Uruguay. Santiago do Chile: OIT, 1999 (Documento de trabajo, 107).

KAZTMAN, R. Notas sobre la medición de la vulnerabilidad social. México: BID-Birf-Cepal, 2000 (Borrador para discusión, 5. Taller regional, la medición de la pobreza, métodos e aplicaciones). Disponível em: 〈www.eclac.cl/deype/noticias/proyectos〉.

KAZTMAN, R.; FILGUEIRA, F. As normas como bem público e privado: reflexões nas fronteiras do enfoque "ativos, vulnerabilidade e estrutura de oportunidades" (AVEO). In: CUNHA, J. M. P. (Org.). Novas metrópoles paulistas: população, vulnerabilidade e segregação. Campinas: Núcleo de Estudos de População/Unicamp, 2006.

LIMA, E. E. C.; BRAGA, F. Da rotatividade migratória a baixa migração: uma análise dos novos padrões da mobilidade populacional no Brasil. In: ENCONTRO NACIONAL DE ESTUDOS POPULACIONAIS, 17. Anais... Caxambu-MG: Abep, 2010.

MARTINE, G. Adaptação dos migrantes ou sobrevivência dos mais fortes? In: MOURA, H. (Org.). Migração interna: textos selecionados. Fortaleza: Banco do Nordeste do Brasil S.A., 1980.

MARQUES, E. Os mecanismos relacionais. Revista Brasileira de Ciências Sociais, v. 22, n. 64, jun. 2007. Disponivel em: 〈http://www.scielo.br/scielo.php?script=sci_arttext\&pid=S0102〉. Acesso em: 08 maio 2009.

. ¿Como son las redes de los individuos en situación de pobreza en el Brasil urbano? Redes, Revista Hispana para el Análisis de Redes Sociales, v. 18, p. 219-251, 2010. 
MASSEY, D. S. et al. Return to aztlan. Los Angeles: University of California Press, 1987.

MATOS, R. Aglomerações urbanas, rede de cidades e desconcentração demográfica no Brasil. In: ENCONTRO NACIONAL DE ESTUDOS POPULACIONAIS, 12. Anais... Caxambu-MG: Abep, 2000.

MATOS, R.; BRAGA, F. Redes sociais, redes territoriais e migrações. In: ENCONTRO NACIONAL DE ESTUDOS POPULACIONAIS, 14. Anais... Caxambu-MG: Abep, 2004.

MONTALI, L. Arranjos familiares: o esforço coletivo para viver na Grande São Paulo. Cadernos de Pesquisa, v. 72, 1990.

PEREIRA, V. B. Os vincados padrões do tecido social: uma analise das vivencias quotidianas de uma freguesia industrializada do Vale do Ave. Porto: Afrontamento, 1999.

PESSAR, P. A. The role of households in international migration and the case of the U.S. - Bound migration from the Dominican Republic. International Migration Review, v. XVI, n. 2, 1982.

PORTES, A. Economic sociology and the sociology of immigration: a conceptual overview. The economic sociology of immigration. Nova York: Russel Sage Foundation, 1995.

RIGOTTI, J. I.; RODRIGUES, R. N. Distribuição espacial da população na Região Metropolitana de Belo Horizonte. In: ENCONTRO NACIONAL DE ESTUDOS POPULACIONAIS, 9. Anais... Belo Horizonte: Abep, 1994.

ROOT, B. D.; DE JONG, G. F. Family migration: conceptualizing the migrating unit in a developing country. In: ENCONTRO ANUAL DA AMERICAN SOCIOLOGICAL ASSOCIATION. Nova York, 1986.

SANTOS, A. P. R. Praia Grande no contexto do processo de metropolização da Baixada Santista: mobilidade populacional e diversidade socioespacial. Dissertação (Mestrado em Demografia) - Instituto de Filosofia e Ciências Humanas, Universidade Estadual de Campinas, Campinas, 2008.

SASAKI, E. M. Dekaseguis: trabalhadores migrantes nipo-brasileiros no Japão. Campinas: Núcleo de Estudos de População/Unicamp, 2000 (Textos Nepo, 39).

SASSEN, S. The mobility of labor and capital. Cambridge: University Press, 1988.

SCHMINK. M. Household economic strategies: a review and research agenda. Latin American Research Review, v. XIX, n. 3, 1984.

SILVA, R. B. Vulnerabilidades e mobilidade pendular na Região Metropolitana da Baixada Santista. Dissertação (Mestrado) - Instituto de Filosofia e Ciências Humanas, Universidade Estadual de Campinas, Campinas, 2009.

SINGER, P. Migrações internas: considerações teóricas sobre o seu estudo. In: MOURA, H. (Org.). Migração interna: textos selecionados. Fortaleza: Banco do Nordeste do Brasil S.A., 1980.

SOARES, W. Da metáfora à substância: redes sociais, redes migratórias e migração nacional e internacional em Valadares e Ipatinga. Tese (Doutorado em Demografia) - Centro de Desenvolvimento e Planejamento Regional, Universidade Federal de Minas Gerias, Belo Horizonte, 2002.

. Para além da concepção metafórica de redes sociais: fundamentos teóricos da circunscrição topológica da migração internacional. In: ENCONTRO NACIONAL DE ESTUDOS POPULACIONAIS. Anais... Belo Horizonte: Abep, 2002.

WOOD, C. Equilibrium and historical perspectives on migration. International Migration Review, v. 16, n. 2, 1982.

YOUNG, A. F.; SANTOS, A. P. R. dos. Desigualdade social, dinâmica populacional e meio ambiente: uma abordagem sobre o processo de urbanização da Região Metropolitana da Baixada Santista. In: ENCONTRO NACIONAL DE ESTUDOS POPULACIONAIS, 16. As desigualdades sócio-demográficas e os direitos humanos no Brasil. Caxambu: Abep, 2008. 
ZÜNDT, C. Baixada Santista: uso, expansão e ocupação do solo, estruturação de rede urbana regional e metropolização. In: CUNHA, J. M. P. (Org.). Novas metrópoles paulistas: população, vulnerabilidade e segregação. Campinas: Núcleo de Estudos de População/Unicamp, 2006.

\begin{abstract}
Intra-urban dynamics and social networks in the Baixada Santista

For quite some time now studies have recognized the importance of processes of spatial redistribution of the population caused by migration flows, and the consequences of migration on urban expansion. The major concern in this paper is to highlight and further circumscribe the scope of studies on flows and movements based on the notion of social networks. This notion has been used since the late 1970s, especially in studies on international migration, but it is still rarely applied to internal migration studies, especially short distance migrations such as intra-metropolitan flows. For this purpose we conducted a study on the Baixada Santista Metropolitan Area (the urban area around the Atlantic Port of Santos, Brazil), based on data from a survey conducted in 2007. This data base gives us details on population mobility in the region and provides interesting information for analyzing factors related to the impact of social networks on migration processes. The survey enabled us to analyze the dynamics of intra-urban and intra-metropolitan mobility based on the concept of vulnerability zones.
\end{abstract}

Keywords: Social networks. Intra-metropolitan mobility. Baixada Santista.

\title{
Resumen
}

\section{Dinámica Intraurbana y redes sociales en la Baixada Santista}

Hace ya bastante tiempo que diversos estudios atribuyen una gran importancia a la redistribución espacial de la población provocada por movimientos migratorios en los procesos de expansión urbana. De este modo, el objetivo principal de este trabajo es destacary delimitar todavía más el estudio de tales flujos y movimientos, a partir de la noción de redes sociales. Noción ya ampliamente utilizada desde fines de la década de 1970 en estudios sobre la migración internacional, pero aún poco apropiada en los trabajos sobre movimientos migratorios internos, principalmente los de corta distancia, tales como los intrametropolitanos. Para ello se utilizan los datos de una encuesta de hogares realizada en 2007, con el propósito de levantar y analizar información más específica sobre tales redes, una vez que ella no existe en las usuales fuentes secundarias de datos. De esta forma, la Región Metropolitana de la Baixada Santista, además de considerarse como un recorte espacial, también es tomada como objeto de estudio del proyecto temático "Vulnerabilidad de las Metrópolis Paulistas". La encuesta de hogares realizada permite asimismo realizar análisis intramunicipales e intraurbanos a partir de las llamadas zonas de vulnerabilidad.

Palabras clave: Redes sociales. Movilidad intrametropolitana. Baixada Santista. 
